\title{
Intravital microscopy in the study of the tumor microenvironment: from bench to human application
}

\author{
Emmanuel M. Gabriel ${ }^{1}$, Daniel T. Fisher ${ }^{2}$, Sharon Evans ${ }^{2}$, Kazuaki Takabe ${ }^{3}$ and \\ Joseph J. Skitzki ${ }^{2,3}$ \\ ${ }^{1}$ Department of Surgery, Section of Surgical Oncology, Mayo Clinic, Jacksonville, FL 32224, USA \\ ${ }^{2}$ Department of Immunology, Roswell Park Cancer Institute, Buffalo, NY 14263, USA \\ ${ }^{3}$ Department of Surgical Oncology, Roswell Park Cancer Institute, Buffalo, NY 14263, USA \\ Correspondence to: Joseph J. Skitzki, email: joseph.skitzki@roswellpark.org \\ Keywords: intravital microscopy; vasculature; lymphocyte; trafficking
}

Received: January 18, $2018 \quad$ Accepted: March 15, $2018 \quad$ Published: April 13, 2018

Copyright: Gabriel et al. This is an open-access article distributed under the terms of the Creative Commons Attribution License 3.0 (CC BY 3.0), which permits unrestricted use, distribution, and reproduction in any medium, provided the original author and source are credited.

\section{ABSTRACT}

Intravital microscopy (IVM) is a dynamic imaging modality that allows for the real time observation of biologic processes in vivo, including angiogenesis and immune cell interactions. In the setting of preclinical cancer models, IVM has facilitated an understanding of the tumor associated vasculature and the role of effector immune cells in the tumor microenvironment. Novel approaches to apply IVM to human malignancies have thus far focused on cancer diagnosis and tumor vessel characterization, but have the potential to provide advances in the field of personalized medicine by identifying individual patients who may respond to systemically delivered chemotherapeutic drugs or immunotherapeutic agents. In this review, we highlight the role that IVM has had in investigating tumor vasculature and the tumor microenvironment in preclinical studies and discuss its current and future applications to directly observe human tumors.

\section{INTRODUCTION}

Intravital microscopy (IVM) is an imaging technique that allows for the real time, direct observation of organic processes in vivo. In contrast to standard conventional microscopic interrogation of fixed tissue sections, IVM allows for a more comprehensive understanding of biologic processes as they occur in the host environment in real time. The dynamic capability of IVM offers several advantages over other traditional in vitro methodologies, such as histopathology, immunohistochemistry (IHC), or flow cytometry, that may only provide information in static snapshots of time. Additionally, unlike other live imaging techniques, such as computerized tomography (CT) scan or magnetic resonance imaging (MRI), IVM allows for high resolution observations at the cellular and subcellular level rather than the organ level [1-4].

The direct visualization of cell populations and their functions in various tissue microenvironments is a powerful tool to dissect complicated and dynamic biological interactions related to tissue metabolism $[5,6]$, remodeling $[7,8]$, angiogenesis $[9,10]$, inflammation $[11,12]$, and immunity $[13,14]$. Moreover, the application of IVM to the study of carcinogenesis has advanced the understanding of several processes involved in the tumor microenvironment [15], including tumor angiogenesis [16], lymphocyte trafficking and infiltration [17], and tumor metastasis [18]. Thus, the greatest attribute of IVM in the study of human disease is the ability to examine biological functions in real time at the cellular level.

Although IVM is an older technique, it has evolved along with conventional microscopy, and thus has been combined with many different visualization methodologies, i.e., bright field, single photon fluorescent imaging, confocal microscopy and multiphoton microscopy [2-4, 19]. IVM has progressed significantly from its beginnings nearly 100 years ago examining the development of blood vessels during tumor formation in rabbit ears [20]. Contemporary IVM can employ 
multiphoton microscopy to allow for clear detection and quantification of multiple fluorescent molecules deep in tissue sites allowing for the discernment of the interactions between a variety of different cell types involved in biologic processes [21, 22]. Multiphoton IVM has emerged in this field as the detection of multiphoton events is limited to a narrowly defined area of the microscopy field, allowing for a deeper observation of tissues to approximately $100-1,000 \mu \mathrm{m}$ in depth [23]. In contrast, traditional confocal microscopy is typically limited to tissue depths less than $100 \mu \mathrm{m}$.

However, it is important to note that the breadth of these advances have largely been achieved in preclinical animal models. To date, there are only a handful of reports demonstrating successful IVM techniques in the study of human cancers, though these pioneering studies highlight the potential of IVM to human disease [24-27]. In this brief review, we discuss the use of IVM to investigate two areas in cancer research: (1) tumor-associated vasculature and its implications on drug delivery and (2) the tumor microenvironment with emphasis of immune cell trafficking and interaction with tumor cells. We highlight the preclinical studies in these two areas where IVM has made significant contributions. Lastly, we present the investigations utilizing IVM in the study of human subjects with cancer. These nascent studies of IVM applied to human disease demonstrate the feasibility and utility of an approach that may lead to breakthroughs in the understanding of human carcinogenesis and anti-tumor therapies.

\section{IVM IN THE STUDY OF TUMOR VASCULATURE}

Angiogenesis is a critical component of tumor growth and is an ideal process for the development of anticancer treatment [28-31]. As cancer cells multiply and divide, they require the formation of new blood vessels in order to obtain nutrients for continued growth [32-35]. Thus, tumor-associated angiogenesis is critical for tumor growth and development. Moreover, cancer cells can also use these vessels to gain access to the systemic circulation, which facilitate intravasation and distant metastases [36]. The importance of angiogenesis in cancer has been exploited by the development of targeted agents against tumor vessel formation. Bevacizumab is a vascular endothelial growth factor (VEGF) antagonist and was the first targeted agent for angiogenesis [37, 38]. There are other anti-angiogenic agents that are currently approved for use in certain countries or being actively investigated in clinical trials. These include endostatin, which is a broad-spectrum endogenous angiogenesis inhibitor [39], and angiostatin, which is an endogenous protein derived from plasminogen that inhibits angiogenesis by targeting vascular endothelial cell growth [40], thalidomide and immunomodulatory drugs (e.g., lenalidomide) which have antiangiogenic properties and inhibit the production of interleukin (IL)-6, which is a growth factor for the proliferation of myeloma cells and other cancers [41].

Key in the development of anti-angiogenesis treatments is the number of differences between tumorassociated vasculature and normal, healthy vessels that have been described [2, 42-45]. Normal vessels are characterized by having a well-defined organization and distribution, non-dilated appearance, normal permeability, complete basement membrane, appropriate expression of endothelial and smooth muscle markers, and a physiologic rate of blood flow. The stromal tissue surrounding normal vessels also usually maintain a low interstitial pressure. In contrast, tumor vasculature is characterized by having a highly disorganized or haphazard distribution with vessels of various shapes and patterns, unusual dilated appearance, high permeability or "leakiness," incomplete or absent basement membranes, abnormally high or low expression of surface markers, and a sluggish or absent rate of blood flow. Many of these characteristics of tumor blood vessels can be directly observed by IVM (Figure 1). In addition, tumor vessels exist within a high surrounding interstitial pressure, which has been termed interstitial hypertension. This interstitial hypertension has been shown to contribute to abnormal blood flow and may hinder the delivery of drugs into the tumor microenvironment [2, 46-49].

The dynamic nature of IVM has provided an understanding of the temporal events that are sequentially involved with tumor angiogenesis and highlighted the differences between normal vessels and tumor vessels. Although these differences have been examined with both conventional methodologies, such as IHC or in vitro models, there are major limitations in ex vivo models, including the inability to fully recapitulate the in vivo biologic architecture and blood flow, reproduce the various important signaling pathways that function in concert to generate angiogenesis, and reestablish the intrinsic biomechanical forces related to tumor vessels, such as interstitial hypertension and blood flow [17, 24, 50]. Conversely, IVM has allowed for the study of tumor angiogenesis during its multiple phases and has increased the understanding of this process in ways that conventional methods are not capable. Using different in vivo animal models, initial signs of tumor angiogenesis and abnormal tumor vasculature have been observed within 2-4 days following tumor implantation [51]. For example, in a heterotopic model of mouse glioma, these events included tumor vessel dilatation and abnormal architectural changes. At day 6 postimplantation, additional tumor vessel aberrancies were characterized, including altered permeability to red blood cells resulting in tumor-associated hemorrhage [10]. As tumors continue to grow, angiogenesis preferentially occurs toward the tumor periphery, whereas the central area becomes increasingly necrotic and less vascularized [52]. This is consistent with the general principles of 
tumor growth established by more conventional methods to study tumors, such as CT scan or histopathology. However, IVM has allowed for a more dynamic and directly observable temporal understanding of tumor angiogenesis over time. This has provided evidence for the different phases of angiogenesis, from early onset to the maturation of tumor vasculature.

The physical parameters of tumor vessel architecture and blood flow have also been extensively studied using IVM. These parameters include blood flow velocity, pressure gradients, and vessel shear, all of which have direct implications on tumor metabolism, oxygenation, immune cell interactions and trafficking, drug delivery, and even angiogenesis itself [53-55]. Following observation and direct capture of fluorescently-enhanced images and videos, post-observational analyses allow for these measurement determinations. Computer software facilitates the calculation of tumor vessel diameter, density, vessel permeability, vascular surface area, flow rates, and resistance [56, 57]. These abnormal values have been characterized and compared to those of normal, healthy vessels, [17, 24, 58] which has provided further insight into the role of tumor vasculature in carcinogenesis.

Based on these observations captured by IVM, investigators have analyzed drug delivery within tumor vasculature and the effects of anti-angiogenic agents on tumor response. Modeling of drug delivery has been significantly enhanced with IVM. Historically, transport of fluorescent molecules was characterized through both the intravascular and interstitial fluid compartments in animal tumor models [2, 6, 17, 43, 47, 54, 59, 60]. Many of the commercially available fluorochromes have molecular weights that are similar to chemotherapeutic agents, which suggests that the delivery of these fluorescent dyes approximate drug delivery. For example, fluorescein and indocyanine green (ICG) have molecular weights of 332 $\mathrm{g} / \mathrm{mol}$ and $775 \mathrm{~g} / \mathrm{mol}$, respectively. These are similar to the molecular weights of various chemotherapeutic drugs, including cyclophosphamide (261 g/mol), oxaliplatin (397 g/mol), doxorubicin (544 g/mol), and irinotecan $(587 \mathrm{~g} / \mathrm{mol})$. Some of these agents, such as doxorubicin, are intrinsically autofluorescent, which facilitates analysis of its delivery and diffusion through tumor vessels into the tumor interstitium [61].

From IVM observation, the permeability of tumor vessels can be calculated and compared to that of normal vessels. Permeability to macromolecules is critical to drug delivery reaching tumor cell targets through the tumor interstitium. Studies have shown that tumor vessels tend to have increased permeability or "leakiness" to macromolecules with molecular weights on the order of 150,000 to $500,000 \mathrm{~g} / \mathrm{mol}$, but that their diffusion is limited by interstitial pressure gradients across the tumor parenchyma and tumor vessels [46, 62]. Thus, novel strategies to optimize drug delivery through manipulation of tumor vessel blood flow and pressure gradients are important for generating anti-tumor responses and can be tested in vivo using IVM $[17,63]$.

Manipulations of the tumor vasculature and drug delivery continue to be developed and interrogated with IVM. Innovative drug delivery systems visualized by IVM utilizing nanoparticles to enhance tumor responses offer unique approaches to augment the efficacy of chemotherapeutic agents [16, 64, 65]. Tumor vessel responses to anti-angiogenic drugs such as bevacizumab can also be directly observed over time with IVM $[55,66]$, which have shown partial restoration of normal vessel permeability and interstitial fluid pressures that equate to enhanced anti-tumor responses. In summary, IVM has and continues to provide novel information regarding tumor vasculature, blood flow, and drug delivery in preclinical cancer models.
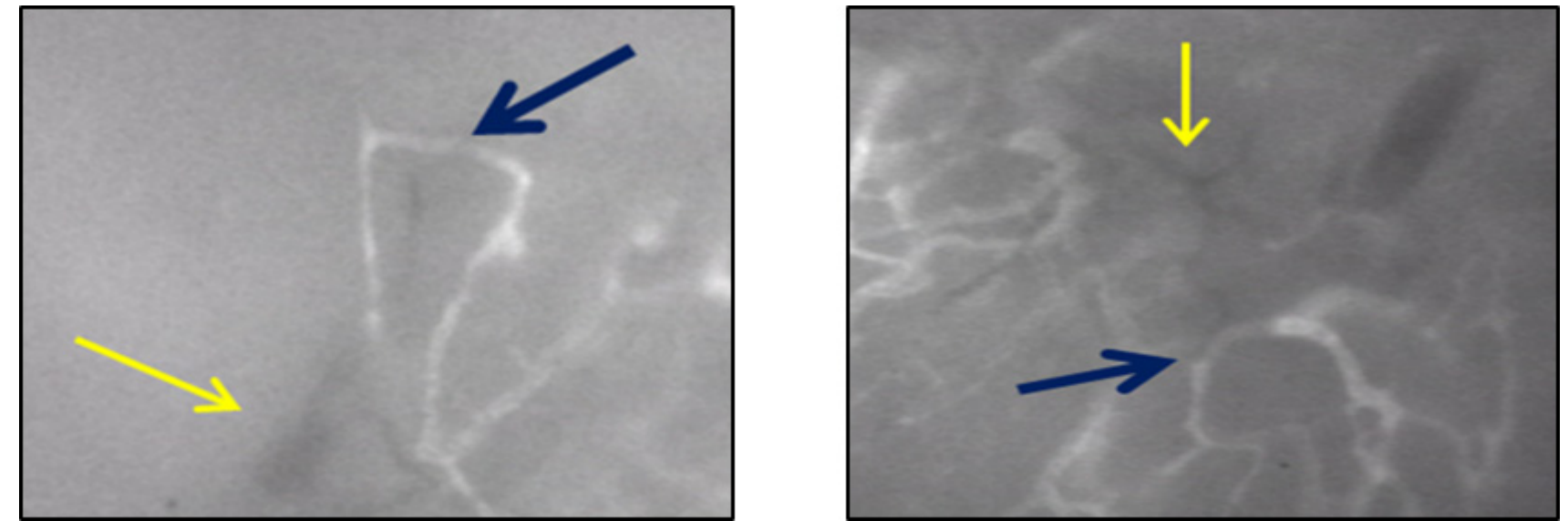

Figure 1: Examples of tumor associated blood vessels as observed in mouse by intravital microscopy (IVM). Tumor vessels are characterized by a haphazard, disorganized distribution, poorly defined branchpoints or multiple vessels intersecting into large, abnormally dilated vessels; and aberrant structural formations such as hairpin loops or circular patterns (blue arrows). Tumor vessels are also characterized by the absence of fluorescent dye uptake suggesting absent or non-detectable flow (yellow arrows). 


\section{IVM IN THE STUDY OF THE TUMOR MICROENVIRONMENT}

Imaging with IVM has provided crucial information with regard to leukocyte migration and trafficking into lymph nodes [67, 68] and tumors [2, 17, 69]. The behavior of immune effector cells using IVM and preclinical tumor animal models in vivo has demonstrated biological differences from their behavior in vitro. Examples of such differences include mechanisms as to how $\mathrm{T}$ cells are activated to kill tumor cells and how leukocyte functionassociated antigen-1 (LFA-1) plays a critical role in leukocyte rolling in vessels [13, 70-72]. A particular advantage of IVM technology is its ability to investigate cell-cell interactions, providing unique insight into the function of immune effector cells against tumor. Fluorescently labeled lymphocytes can be directly observed by IVM to traffic along tumor microvasculature, and various interventions can be tested in order to determine the optimal regional signals that support tumor infiltrating lymphocytes [17]. Similarly, myeloid derived immune cells including monocytes and macrophages have also been studied in the tumor microenvironment using IVM [15].

It has been well established that CD8+ effector $\mathrm{T}$ cells play a significant role in the adaptive tumor immunity response through their production of interferongamma (IFN- $\gamma$ ) and initiation of the Fas ligand-dependent cytolytic pathway following $\mathrm{T}$ cell receptor (TCR) interaction and activation with tumor antigen $[73,74]$. The infiltration of CD8+ T cells into various tumor types have been correlated with improved clinical outcomes for patients with melanoma, breast cancer, and malignancies of gastrointestinal origin [75-80]. Lymphocyte trafficking is a critical precursor to infiltration into tumor as effector $\mathrm{T}$ cells need to home in to cancer sites in order to deliver their anti-tumor effects. Cell adhesion molecules, such as intracellular adhesion molecule-1 (ICAM-1) involved in lymphocyte firm adhesion to tumor vessels that precedes diapedesis into the tumor interstitium, have been shown to play important roles in lymphocyte trafficking [81]. Although transcriptional profiling studies have identified ICAM-1 and other surface molecules that influence $\mathrm{T}$ cell migration, one of the previous major gaps in the understanding of effector cell trafficking to the tumor microenvironment was determining whether these events could be manipulated in order to optimize tumor responses to effector cell function. Furthermore, the temporal sequence of events with respect to leukocyte trafficking and tumor infiltration has also been better characterized with IVM, highlighting another advantage of this technique.

Using IVM to track fluorescently labeled adoptively transferred lymphocytes, investigators have directly addressed these issues. Fisher et al. showed that effector $\mathrm{T}$ cell trafficking and infiltration into tumors was limited despite the presence of proinflammatory cytokines such as IFN- $\gamma$ [17]. The application of a thermal stimulus resulted in increased signaling through the interleukin-6 (IL-6) pathway and modified the tumor vasculature with the end result of increased effector $\mathrm{T}$ cell trafficking and infiltration into target tumor, which could be directly observed and quantified in real time using IVM (Figure 2). Mechanistically, this was accomplished through a combination of increased selectin and ICAM1 expression, promoting extravasation of effector and memory $T$ cells in tumor tissue $[17,82]$. A decrease in the infiltration of regulatory $\mathrm{T}$ cells (Tregs) was also noted, further favoring an anti-tumor response within the tumor microenvironment. Xu et al. later showed that IVM could be used to investigate other signaling molecules involved with $\mathrm{T}$ cell trafficking using a constructed photoactivable (PA) chemokine C-X-C motif receptor 4 (PA-CXCR4). CXCR4 along with other chemokines like CXCR3 has been shown to play an important role in lymphocyte trafficking and immunosurveillance [82-84]. Using a mouse melanoma model, the PA-CXCR4 construct was shown to transmit intracellular CXCR4 signals in response to a 505-nm light stimulus, resulting in activation of $\mathrm{T}$ cell polarization and migration to tumor [85]. This approach improved the efficacy of adoptive $\mathrm{T}$ cell transfer with a significant reduction in tumor growth in vivo. These findings suggested that the use of photoactivatable chemokine receptors influenced lymphocyte trafficking with outstanding spatial resolution in tissues. Similar to the study by Fisher et al. which targeted IL-6 signaling to improve the delivery of effector $\mathrm{T}$ cells into the tumor, the work by Xu et al. represents another strategy in optimizing $\mathrm{T}$ cell trafficking and infiltration to tumors, utilizing IVM as a means to demonstrate such observations.

In addition to lymphocyte trafficking and infiltration, IVM has also allowed for the study of tumor associated macrophages (TAMs). IVM has been used to elucidate various functions of TAMs in vivo, ranging from phagocytosis of antibody labeled tumor cells to interactions with tumor and other immune cells within the tumor microenvironment [86]. The latter function of TAMs has been observed with IVM at several in vivo locations, including the tumors themselves, tumor draining lymph nodes (TDLNs), and secondary lymphoid organs including the liver and spleen [15]. For example, studies utilizing IVM have shown that TAMs interact with T cells at high endothelial venules (HEVs) located in proximity to TDLNs, where tumor antigen presentation occurs $[87,88]$. This interaction within TDLNs has been observed in as little as 8 hours following adoptive transfer of $\mathrm{T}$ cells and tumor antigen pulsed dendritic cells $[89,90]$. The amount of interaction then increases substantially over the next several hours, forming a network of steady-state antigen presenting cells (APCs) for trafficking lymphocytes [91, 92]. Tumor-draining lymph nodes were also found to have diminished expression of CCL21, a chemokine critical for $\mathrm{T}$ cell trafficking resulting in decreased 
interactions between circulating $\mathrm{T}$ cells and lymph node vessels by IVM [93]. These studies have highlighted the unique use of IVM to characterize the temporal sequence of events involved in tumor antigen presentation and downstream migration of programmed $\mathrm{T}$ cells.

Using IVM, TAMs have also been observed to play important immunosuppressive roles at tumor sites [94]. In a study using a murine breast cancer model and multiphoton microscopy, TAMS were identified at the edges of tumors and shown to migrate in association with tumor growth at the periphery [95]. Interestingly, perivascular macrophages within the breast tumors were associated with tumor cell intravasation even in the absence of regional tumor angiogenesis, further supporting a role for TAM-promoting tumorigenesis and metastasis. Mechanistically, this pattern of co-migration between TAMS and breast tumor cells was dependent on macrophage-derived epidermal growth factor (EGF) and tumor cell-derived colony stimulating factor 1 (CSF1), which were shown to create a paracrine signaling loop between the tumor cells and TAMs [95-98]. Impairment of these TAMS using clodronate liposomes was shown to significantly decrease tumor cell motility and intravasation, providing evidence that TAMS could be targeted in the tumor microenvironment and that this approach could be observed directly with IVM [99, 100]. Thus, these TAM-associated mechanisms of tumorigenesis represent novel targets for therapy, for which IVM offers a unique role in their testing. Recent preclinical studies have highlighted this potential where macrophages were imaged eliminating circulating tumor cells following antibody therapy [101].

Similar to the interaction of TAMS with tumor cells to promote local tumor growth, metastases originating from the tumor microenvironment have also been an area where IVM has provided new insight [18, 102].

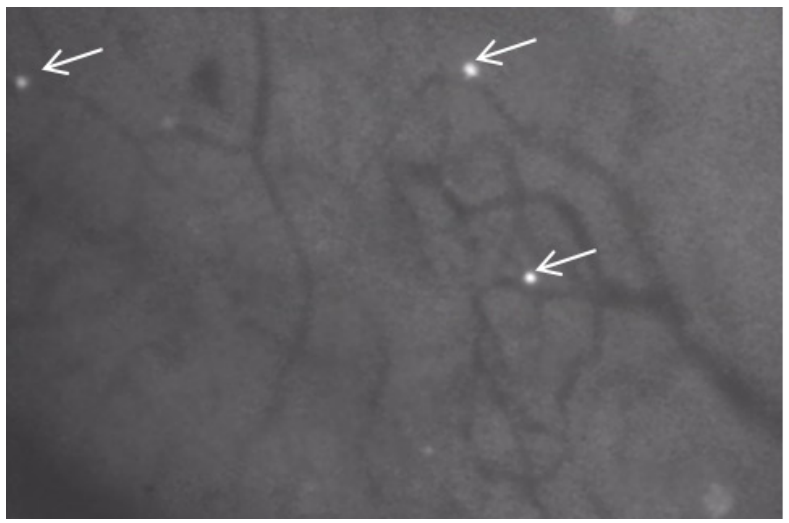

Like previous studies examining the periphery of tumors, preclinical models utilizing IVM have shown that the tumor margin contains functional lymphatic vessels that may represent regions where lymphatic metastases can occur [103]. A number of studies using IVM have characterized the mechanistic signaling pathways required for the entry of tumor cells into the regional lymphatics. A prominent example of one signaling pathway involved in tumor intravasation was studied by Giampieri et al., which comprised a transforming growth factor- $\beta$ (TGF- $\beta$ ) signaling cascade promoting Smad4 and epidermal growth factor receptor (EGFR) mediated downstream activation in a breast cancer model [104]. Using a construct of Smad4 fused to green fluorescent protein (GFP), expression of TGF- $\beta$ could be quantified, and this was directly associated with single tumor cell motility and intravasation into blood vessels as observed by IVM. Further work by this group and others have shown that blockade of TGF- $\beta$ can abrogate TGF- $\beta$-mediated tumor motility and intravasation into blood vessels seen by IVM, although other mechanisms of tumor cell motility may persist and lead to intravasation into tumor lymphatics [105, 106]. IVM has even been used to show how neutrophils can promote liver metastasis through interactions with circulating tumor cells [107].

Thus, in addition to the study of tumor vasculature, IVM has enabled multiple advances in the study of the tumor microenvironment, specifically in regards to tumor and immune cell interactions. Effector cell trafficking can be directly observed, which provides an important platform to study novel therapies to increase or optimize effector trafficking with the goal of augmenting anti-tumor responses. Mechanisms of tumor cell intravasation into blood vessels or lymphatics, as observed by IVM in real time, have likewise presented opportunities to study the early events of metastasis and strategies to prevent them.

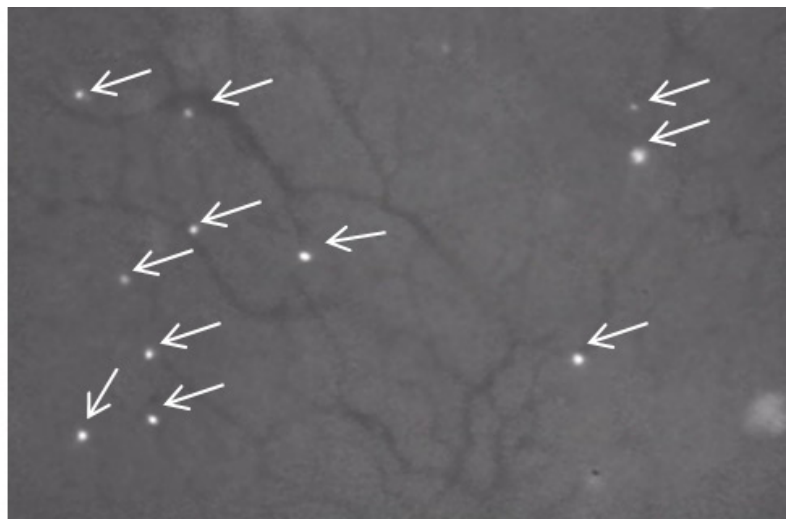

Figure 2: Examples of fluorescently labeled (fluorescein) lymphocytes trafficking to tumor in a mouse model as observed by IVM. Lymphocyte behavior is captured in real time by IVM. Advantages of IVM in this tumor model include its high resolution to observe cell-to-cell interactions and to follow the number of events over time in response to different experimental or therapeutic interventions. White arrows highlight the infiltration of fluorescein labeled trafficking lymphocytes. In this case, the number of infiltrating lymphocytes was increased in response to a thermal stimulus. Left panel: before thermal stimulus; Right panel: after thermal stimulus. 


\section{HUMAN APPLICATIONS OF IVM}

While IVM has been extensively utilized in preclinical animal models to study tumor vessels and the tumor microenvironment, the direct use of IVM in human subjects has been much less prevalent. However, novel applications of IVM have been reported and show promise for translational impact of IVM in the study of human diseases, particularly in regard to tumor vasculature and the tumor microenvironment. Specifically, IVM techniques have been applied to the endoscopic evaluation of gastrointestinal tumors (originating from the esophagus or colon), the cystoscopic evaluation of bladder urothelial cancer, and most recently to melanoma, including primary tumors or in-transit lesions, as summarized in Table 1. The superficial or endoluminal location of these tumor types facilitates direct observation with IVM and has helped to demonstrate the feasibility and applicability of IVM in human subjects.

With regard to gastrointestinal endoluminal tumors, IVM has been directed to tumors of the esophagus or colon via endoscopy [108]. Parallel to in vitro observations, endoscopic imaging technology, or endomicroscopy, has been demonstrated in numerous studies to be feasible for the in vivo observation of cellular morphology of the mucosa in the upper and lower gastrointestinal tract at the cellular and subcellular level $[109,110]$. Differences in nuclear and cellular morphology between normal and aberrant cells, enhanced with intravenous (IV) administration of fluorescein, have been strongly correlated with the diagnosis of neoplasia [27]. In the upper gastrointestinal tract, endomicroscopy distinguished between normal mucosa and Barrett's esophagus with sensitivity and specificity each over 90\% [110]. Detection of early human gastric cancer has also been shown to be feasible, which in some instances has not required enhancement with IV fluorescein injection [111]. In the lower gastrointestinal tract, differentiation of neoplastic versus non-neoplastic colonic polyps has also been demonstrated with high sensitivity and specificity (greater than 90\%) using endomicroscopy [112]. Furthermore, several studies have reported the feasibility of differentiating dysplastic cells from normal cells by conjugating fluorescent peptides to precancerous or cancer cells. This technique has further facilitated the detection of dysplastic areas by IVM in patients with either colon or esophageal malignancies confined to the mucosa [113-115].

For bladder urothelial tumors, IVM has similarly been directed to the bladder urothelium via cystoscopy [116]. The main function of IVM in this setting has been to predict which areas of the bladder urothelium are malignant. Small, reusable imaging probes ranging in diameter from $0.85 \mathrm{~mm}$ to $2.6 \mathrm{~mm}$ can be inserted into the working channels of standard cystoscopes [117] Based on fluorescence confocal microscopy in patients who received IV fluorescein, real time IVM of normal urothelium, carcinoma in situ, and low-grade and high- grade carcinoma have been correlated to results obtained with conventional histopathology $[118,119]$. Using highquality imaging and post-acquisition analysis, differences were categorized among the observed IVM images in relation to histopathological diagnoses. Interestingly, the ability to identify these different characteristics using IVM was consistent among novice and more expert urologists using cystoscopy, suggesting that IVM techniques may have a favorable learning curve [118]. Similar to the gastrointestinal tumors, fluorescently labeled antibodies specific to bladder tumor antigens, such as CD47, have also been employed to enhance the intravital imaging of urothelial tumors [25].

In addition to these endoscopic and cystoscopic techniques, Fisher et al recently demonstrated the feasibility of IVM for patients with melanoma [24]. In this study, the authors used a patented, operating room (OR) compatible, mobile confocal microscope (Figure 3 ) in order to perform direct observation of patient tumor vasculature associated with primary melanoma or in transit disease. The aims of this clinical trial were to measure tumor diameter and blood flow delineated by IV fluorescein. Interestingly, up to $50 \%$ of tumor vessels did not support blood flow as determined by the absence of detectable fluorescein (Figure 4) [24]. To determine how these intraoperative observations compared with standard pathologic evaluation, tumor specimens from the same patients were analyzed to calculate vessel diameter, which showed that vessel diameters in vivo were on average twice as large as that found on IHC. Tissue shrinkage by pathologic preparation as well as the natural distention of vessels in vivo likely contributed to these differences in vessel size between real time IVM and pathologic measurements. Regardless of the reasons for this discrepancy, the larger size has important implications on blood flow and thereby on drug delivery that would be estimated based on histologic measurements of tumor vessel diameter and the previously discussed preclinical models. Following this clinical trial, this group is continuing the application of IVM to human subjects by performing real time, intraoperative observations of the vasculature associated with the sentinel draining lymph node (SLN) of patients with primary melanoma (NCT02857374) and in patients with primary peritoneal, fallopian tube, or ovarian cancer (NCT03297489). The human intravital microscope interfaces with the lymph node during the patients planned sentinel lymph node biopsy (Figure 5). Characteristics of the SLN associated vessels may have the future potential to serve as a biomarker for melanoma severity or prognosis when used in conjunction with other disease parameters. Similarly, the microscope interfaces with the peritoneal lining of patients with select peritoneal surface malignancies to evaluate tumor implant associated vessels.

This early study in human IVM for melanoma as well as the more established use of confocal microscopy in endoscopy and cystoscopy comprises the current applications of IVM in human patients. From these 


\begin{tabular}{|c|c|c|c|c|}
\hline Investigator Reference & Disease Site & Device & Feasibility & $\begin{array}{l}\text { Differentiate normal } \\
\text { tissue from pre- } \\
\text { cancer/cancer }\end{array}$ \\
\hline Kiesslich et al. [110] & Esophagus & $\begin{array}{l}\text { Confocal laser } \\
\text { endomicroscope } \\
\text { (Pentax and Optiscan) }\end{array}$ & Yes & Yes \\
\hline Nakao et al. [111] & Stomach & $\begin{array}{l}\text { Confocal laser } \\
\text { endomicroscope } \\
\text { (Mauna Kea Technologies } \\
\text { and Fujinon) }\end{array}$ & Yes & Yes \\
\hline Wallace et al. [27] & Esophagus and Colon & $\begin{array}{l}\text { Confocal laser } \\
\text { endomicroscope } \\
\text { (Mauna Kea Technologies) }\end{array}$ & Yes & Yes \\
\hline Xie et al. [112] & Colon & $\begin{array}{l}\text { Confocal laser } \\
\text { endomicroscope } \\
\text { (Pentax) }\end{array}$ & Yes & Yes \\
\hline Wu et al. [119] & Bladder & $\begin{array}{l}\text { Confocal laser } \\
\text { endomicroscope } \\
\text { (Mauna Kea Technologies) }\end{array}$ & Yes & Yes \\
\hline Fisher et al. [24] & Skin (Melanoma) & $\begin{array}{l}\text { Roswell Park Cancer } \\
\text { Institute (RPCI) intra- } \\
\text { operative microscope }\end{array}$ & Yes & Not performed \\
\hline
\end{tabular}

HIVM has been used to study human malignancies in a variety of organ sites. The surface or lumenal nature of these malignancies facilitates the interface between the microscopic objective and the tumor cells. Observations are feasible in real time and can often differentiate between normal versus abnormal tissue.

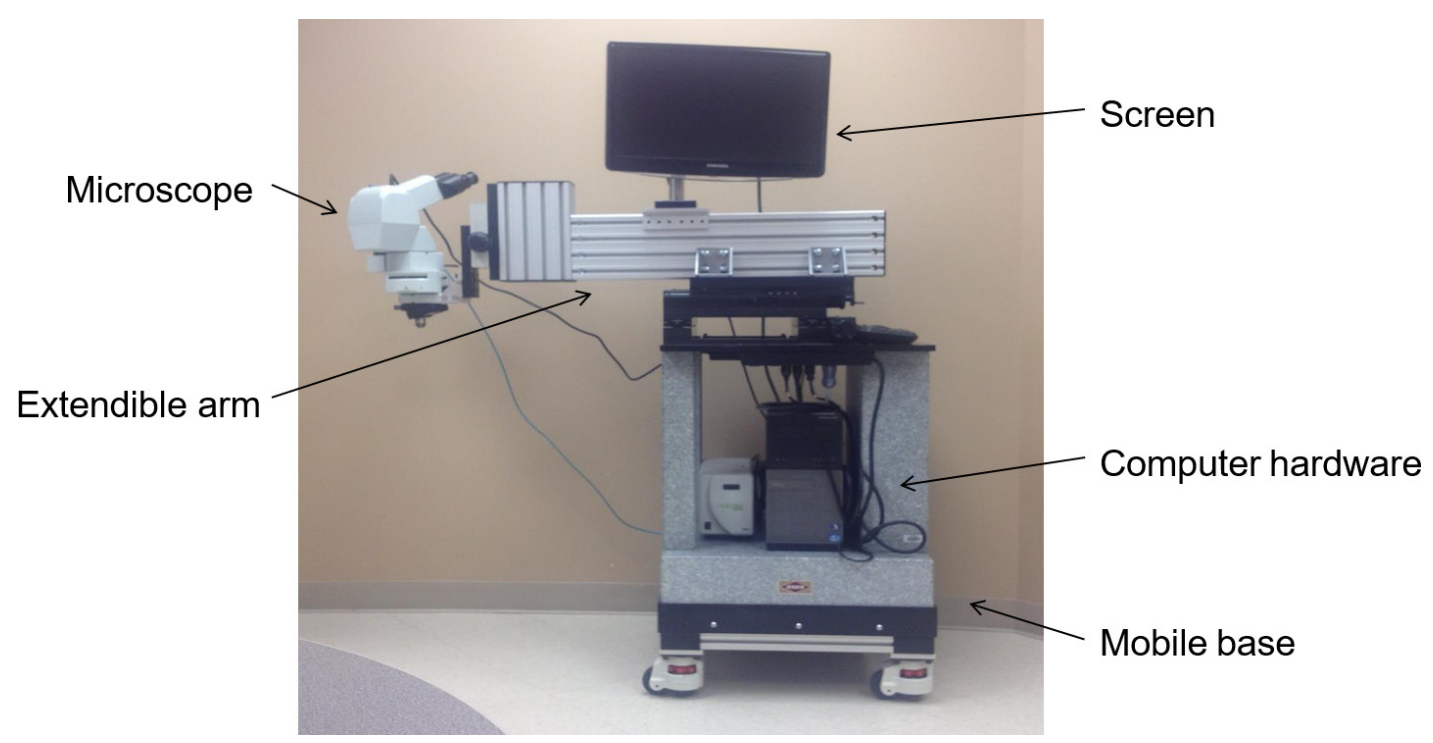

Figure 3: Depiction of the novel intravital microscope for human use. Fisher et al have developed a portable, intravital microscope capable of interfacing with human tumors in real time during surgical resection in the operating room. The microscope and associated video microscopy hardware/software are wheel mounted to a solid granite base weighing over $360 \mathrm{~kg}$, allowing for portability and stability during the IVM observation. The microscope objective lenses are placed on an extendable cantilevered arm to physically reach different anatomical areas of the patient. 
studies, advances have been made in the understanding of tumor vasculature and the diagnosis of endoluminal cancers. Further innovation with IVM holds promise to provide a greater understanding of human cancers and possibly optimization of responses to drug delivery.

\section{THE FUTURE OF IVM IN THE STUDY OF HUMAN CANCERS}

Whereas the use of IVM has thus far been limited to observational and diagnostic applications, this innovative technology holds potential to further the understanding of human cancers and examine responses to chemotherapies and immunotherapies. While the first applications of fluorescent confocal microscopy were demonstrated in gastrointestinal mucosa and then duplicated for urothelial mucosa, the feasibility of IVM using an innovative intraoperative microscope has now opened a realm of possibility to investigate other primary malignancies. Some of the human cancers that may be amenable to IVM observation include inflammatory breast cancer or peritoneal surface malignancies or other etiologies, including colorectal or gastric cancers.
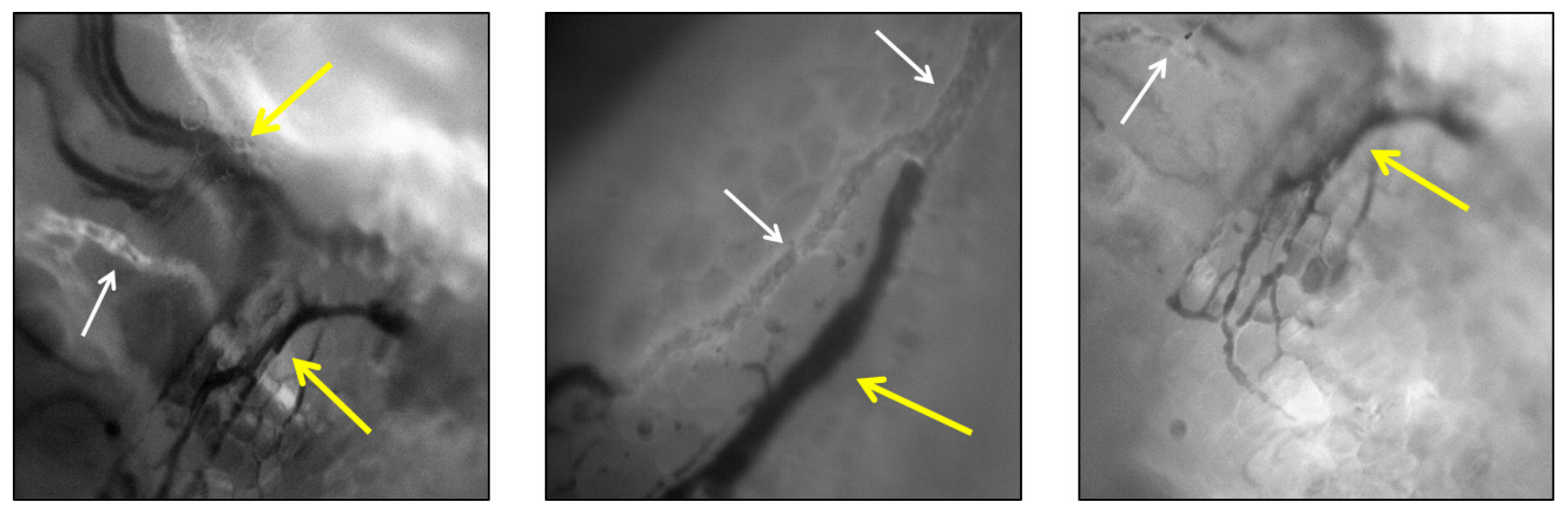

Figure 4: Examples of patient melanoma associated tumor vessels as directly observed by IVM in real time. Interestingly, approximately $50 \%$ of these vessels are nonfunctional in that they do not have blood flow, supported by the observation that fluorescein is not present within the lumen of these vessels (yellow arrows). Normal appearing vessels are also present (white arrows). This new observation has implications for drug delivery to target tumor as patients with a high proportion of nonfunctional tumor associated vessels may have limitations in drug delivery and therefore drug efficacy.

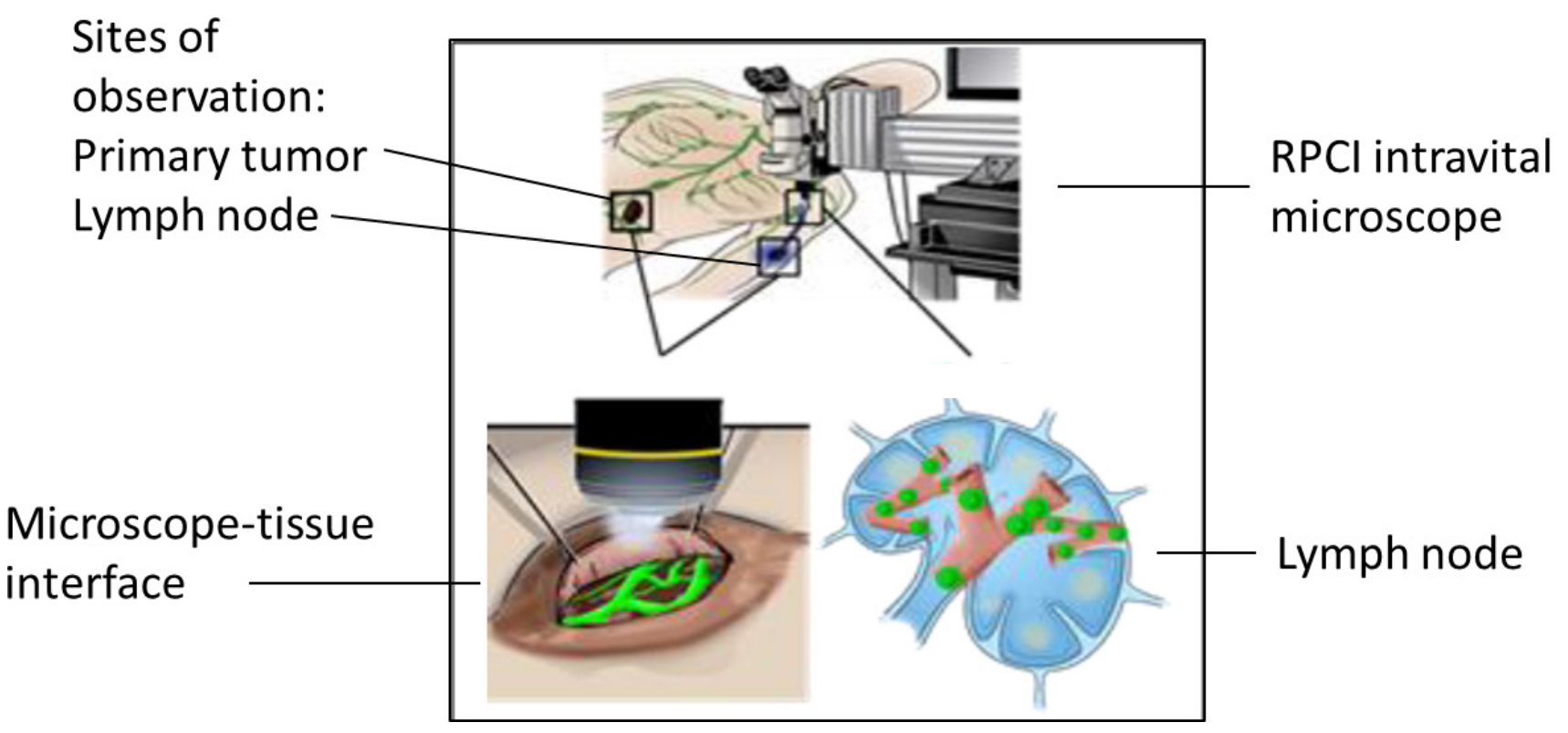

Figure 5: Schematic of ongoing clinical trial (NCT02857374), which is investigating the microvasculature associated with the primary tumor and the sentinel lymph node (SLN) of patients with melanoma who meet criteria for SLN biopsy. In this illustration, the mobile intravital microscope interfaces with both the primary tumor (left lower panel) and the dissected SLN in the axilla (right lower panel). Nodal vessels and lymphatics are observed and correlated to node positivity. 
Inflammatory breast cancer is an aggressive form of invasive breast cancer and is characterized by tumor infiltration of the lymphatics resulting in an erythematous phenotype with dilated microvasculature $[120,121]$. These characteristics make inflammatory breast cancer an ideal tumor type to be observed by IVM. This would allow the investigation of tumor associated blood vessels and lymphatics with respect to organization and blood flow. It may be reasonable to hypothesize that the nonfunctional proportion of vessels and lymphatics in inflammatory breast cancer may be similar to the $50 \%$ observed in melanoma by Fisher et al, and this would have important implications on drug delivery for this aggressive disease. Real time imaging of inflammatory breast cancer using IVM in humans has not yet been performed, but could be utilized during the delivery of neoadjuvant chemotherapy.

Similar to breast cancer, peritoneal carcinomatosis of gastrointestinal origin represents an additional surface malignancy that may be observed by IVM. Peritoneal carcinomatosis comprises a variety of tumors, which as a group are difficult to treat and typically are minimally responsive to systemic chemotherapy [122-124]. Cytoreductive surgery with hyperthermic intraperitoneal chemotherapy (CRS/HIPEC) may offer advantages over systemic treatment, though this has been associated with significant morbidity [125, 126]. Quantification of blood flow to peritoneal implants in real time can provide critical information on whether these tumors would be expected to respond to systemically delivered therapies. Nonfunctional vessels associated with peritoneal carcinomatosis would provide further rationale for the poor drug delivery and tumor response observed clinically.

Inherent to the use of IVM in any of these tumor types is the innovative application of this imaging technology to provide personalized precision medicine for patients with cancer [127]. For observable surface malignancies, determination of tumor vessel functionality can help guide individualized treatment by identifying which patients would be expected to sustain drug delivery. This could be particularly relevant for systemically delivered chemotherapy. Using inflammatory breast cancer as the example, the autofluorescent drug doxorubicin may be able to be tracked to tumor using human IVM technology. For drugs that are not intrinsically autofluorescent, fluorescein or ICG may be used as surrogates for drug delivery. Strategies to restore or enhance blood flow may also be tested in real time using IVM to optimize individualized drug delivery and response.

In addition to chemotherapy, immunotherapy can be investigated directly using IVM. Checkpoint inhibitors have comprised a major paradigm shift in the treatment of melanoma and are being investigated in many other cancers [128, 129]. As an immunotherapeutic agent, ipilimumab is a monoclonal antibody against cytotoxic T Lymphocyte Associated Antigen-4 (CTLA-4), the expression of which is mechanistically associated with anergy to tumor-associated antigens [130]. Targeted blockade of CTLA-4 led to unprecedented responses in metastatic malignant melanoma [131]. Treatment with pembrolizumab, an antibody against the programmed cell death 1 (PD-1) receptor, has been even more successful than ipilimumab and is associated with a more favorable toxicity profile, thus supplanting ipilimumab as the first line agent for patients with metastatic melanoma [132]. However, durable responses with these agents are still limited, and many patients develop resistance to these therapies [133]. To address these individualized patient issues, IVM may be used to demonstrate trafficking and infiltration of fluorescently labeled, adoptively transferred effector cells to tumor targets in order identify patients with the potential to respond to immunotherapeutics. Consistent with the emerging realm of personalized medicine, IVM may be able to select patients who will respond to different anti-tumor therapies in order to provide the most effective treatments.

In conclusion, many advances in the understanding of tumor vasculature and immune cell functions in the tumor microenvironment have been made using IVM, largely in preclinical models. While most of the applications of IVM to human malignancies have involved the detection of tumor cells or the observation of tumor associated vessels, current innovations offer the potential to expand the clinical use of IVM. These future novel directions for IVM may have important implications for personalized medicine and include the study of tumor vessel modulation to augment drug delivery and the role of fluorescently labeled immune effector cells in human tumors.

\section{Abbreviations}

ICG: indocyanine green; IVM: intravital microscopy; PA: photoactivable; SLN: sentinel lymph node; TAM: tumor associated macrophages; TDLN: tumor draining lymph node; Treg: regulatory T cell.

\section{Author contributions}

EG, DT, SE, JS, and KT contributed to the manuscript conception and design. EG drafted the manuscript. DT and SE provided the Figures. JS, DT, SE, and KT provided critical revision.

\section{CONFLICTS OF INTEREST}

None.

\section{REFERENCES}

1. Kikuta J, Ishii M. Recent advances in intravital imaging of dynamic biological systems. J Pharmacol Sci. 2012; 119:193-7. 
2. Jain RK, Munn LL, Fukumura D. Dissecting tumour pathophysiology using intravital microscopy. Nat Rev Cancer. 2002; 2:266-76.

3. Pittet MJ, Weissleder R. Intravital imaging. Cell. 2011; 147:983-91.

4. Secklehner J, Lo Celso C, Carlin LM. Intravital microscopy in historic and contemporary immunology. Immunol Cell Biol. 2017; 95:506-13.

5. Helmlinger G, Yuan F, Dellian M, Jain RK. Interstitial pH and $\mathrm{pO} 2$ gradients in solid tumors in vivo: high-resolution measurements reveal a lack of correlation. Nat Med. 1997; $3: 177-82$.

6. Dewhirst MW, Ong ET, Braun RD, Smith B, Klitzman B, Evans SM, Wilson D. Quantification of longitudinal tissue pO2 gradients in window chamber tumours: impact on tumour hypoxia. Br J Cancer. 1999; 79:1717-22.

7. Billaud M, Ross JA, Greyson MA, Bruce AC, Seaman SA, Heberlein KR, Han J, Best AK, Peirce SM, Isakson BE. A new method for in vivo visualization of vessel remodeling using a near-infrared dye. Microcirculation. 2011; 18:163-71.

8. Lohela M, Werb Z. Intravital imaging of stromal cell dynamics in tumors. Curr Opin Genet Dev. 2010; 20:72-8.

9. McDonald DM, Choyke PL. Imaging of angiogenesis: from microscope to clinic. Nat Med. 2003; 9:713-25.

10. Vajkoczy $P$, Schilling L, Ullrich A, Schmiedek $P$, Menger MD. Characterization of angiogenesis and microcirculation of high-grade glioma: an intravital multifluorescence microscopic approach in the athymic nude mouse. J Cereb Blood Flow Metab. 1998; 18:510-20.

11. Aikawa E, Nahrendorf M, Figueiredo JL, Swirski FK, Shtatland T, Kohler RH, Jaffer FA, Aikawa M, Weissleder R. Osteogenesis associates with inflammation in early-stage atherosclerosis evaluated by molecular imaging in vivo. Circulation. 2007; 116:2841-50.

12. Weissleder R, Nahrendorf M. Advancing biomedical imaging. Proc Natl Acad Sci U S A. 2015; 112:14424-8.

13. Sumen C, Mempel TR, Mazo IB, von Andrian UH. Intravital microscopy: visualizing immunity in context. Immunity. 2004; 21:315-29.

14. Germain RN, Castellino F, Chieppa M, Egen JG, Huang AY, Koo LY, Qi H. An extended vision for dynamic highresolution intravital immune imaging. Semin Immunol. 2005; 17:431-41.

15. Rua R, McGavern DB. Elucidation of monocyte/ macrophage dynamics and function by intravital imaging. J Leukoc Biol. 2015; 98:319-32.

16. Kirui DK, Ferrari M. Intravital Microscopy Imaging Approaches for Image-Guided Drug Delivery Systems. Curr Drug Targets. 2015; 16:528-41.

17. Fisher DT, Chen Q, Skitzki JJ, Muhitch JB, Zhou L, Appenheimer MM, Vardam TD, Weis EL, Passanese J, Wang WC, Gollnick SO, Dewhirst MW, Rose-John S, et al. IL-6 trans-signaling licenses mouse and human tumor microvascular gateways for trafficking of cytotoxic T cells. J Clin Invest. 2011; 121:3846-59.

18. Beerling E, Ritsma L, Vrisekoop N, Derksen PW, van Rheenen J. Intravital microscopy: new insights into metastasis of tumors. J Cell Sci. 2011; 124:299-310.

19. Menger MD, Lehr HA. Scope and perspectives of intravital microscopy--bridge over from in vitro to in vivo. Immunol Today. 1993; 14:519-22.

20. Sandison JC. A new method for the microscopic study of living growing tissues by the introduction of a transparent chamber in the rabbit's ear. Anat Rec. 1924; 28.

21. Denk W, Strickler JH, Webb WW. Two-photon laser scanning fluorescence microscopy. Science. 1990; 248:73-6.

22. Cahalan MD, Parker I, Wei SH, Miller MJ. Two-photon tissue imaging: seeing the immune system in a fresh light. Nat Rev Immunol. 2002; 2:872-80.

23. Wang BG, Konig K, Halbhuber KJ. Two-photon microscopy of deep intravital tissues and its merits in clinical research. $\mathrm{J}$ Microsc. 2010; 238:1-20.

24. Fisher DT, Muhitch JB, Kim M, Doyen KC, Bogner PN, Evans SS, Skitzki JJ. Intraoperative intravital microscopy permits the study of human tumour vessels. Nat Commun. 2016; 7:10684.

25. Pan Y, Volkmer JP, Mach KE, Rouse RV, Liu JJ, Sahoo D, Chang TC, Metzner TJ, Kang L, van de Rijn M, Skinner EC, Gambhir SS, Weissman IL, Liao JC. Endoscopic molecular imaging of human bladder cancer using a CD47 antibody. Sci Transl Med. 2014; 6:260ra148.

26. Paramsothy S, Leong RW. Endoscopy: Fluorescein contrast in confocal laser endomicroscopy. Nat Rev Gastroenterol Hepatol. 2010; 7:366-8.

27. Wallace MB, Meining A, Canto MI, Fockens P, Miehlke S, Roesch T, Lightdale CJ, Pohl H, Carr-Locke D, Löhr M, Coron E, Filoche B, Giovannini M, et al. The safety of intravenous fluorescein for confocal laser endomicroscopy in the gastrointestinal tract. Aliment Pharmacol Ther. 2010; 31:548-52.

28. Ramanathan R, Olex AL, Dozmorov M, Bear HD, Fernandez LJ, Takabe K. Angiopoietin pathway gene expression associated with poor breast cancer survival. Breast Cancer Res Treat. 2017; 162:191-98.

29. Mukhopadhyay P, Ramanathan R, Takabe K. S1P promotes breast cancer progression by angiogenesis and lymphangiogenesis. Breast Cancer Manag. 2015; 4:241-4.

30. Nagahashi M, Ramachandran S, Kim EY, Allegood JC, Rashid OM, Yamada A, Zhao R, Milstien S, Zhou H, Spiegel S, Takabe K. Sphingosine-1-phosphate produced by sphingosine kinase 1 promotes breast cancer progression by stimulating angiogenesis and lymphangiogenesis. Cancer Res. 2012; 72:726-35.

31. Takabe K, Spiegel S. Export of sphingosine-1-phosphate and cancer progression. J Lipid Res. 2014; 55:1839-46.

32. McDougall SR, Anderson AR, Chaplain MA. Mathematical modelling of dynamic adaptive tumour-induced angiogenesis: 
clinical implications and therapeutic targeting strategies. J Theor Biol. 2006; 241:564-89.

33. Carmeliet P, Jain RK. Angiogenesis in cancer and other diseases. Nature. 2000; 407:249-57.

34. De Palma M, Biziato D, Petrova TV. Microenvironmental regulation of tumour angiogenesis. Nat Rev Cancer. 2017; 17:457-74.

35. Folkman J. Angiogenesis. Annu Rev Med. 2006; 57:1-18.

36. Flamini V, Jiang WG, Lane J, Cui YX. Significance and therapeutic implications of endothelial progenitor cells in angiogenic-mediated tumour metastasis. Crit Rev Oncol Hematol. 2016; 100:177-89.

37. Rosen LS. VEGF-targeted therapy: therapeutic potential and recent advances. Oncologist. 2005; 10:382-91.

38. Stevenson CE, Nagahashi M, Ramachandran S, Yamada A, Bear HD, Takabe K. Bevacizumab and breast cancer: what does the future hold? Future Oncol. 2012; 8:403-14.

39. Cao Y. Molecular mechanisms and therapeutic development of angiogenesis inhibitors. Adv Cancer Res. 2008; 100:113-31.

40. Kurup A, Lin C, Murry DJ, Dobrolecki L, Estes D, Yiannoutsos CT, Mariano L, Sidor C, Hickey R, Hanna N. Recombinant human angiostatin (rhAngiostatin) in combination with paclitaxel and carboplatin in patients with advanced non-small-cell lung cancer: a phase II study from Indiana University. Ann Oncol. 2006; 17:97-103.

41. Anderson KC. Lenalidomide and thalidomide: mechanisms of action-similarities and differences. Semin Hematol. 2005; 42:S3-8.

42. Cao Y. Tumor angiogenesis and molecular targets for therapy. Front Biosci. 2009; 14:3962-73.

43. Brizel DM, Klitzman B, Cook JM, Edwards J, Rosner G, Dewhirst MW. A comparison of tumor and normal tissue microvascular hematocrits and red cell fluxes in a rat window chamber model. Int J Radiat Oncol Biol Phys. 1993; 25:269-76.

44. Chambers AF, Groom AC, MacDonald IC. Dissemination and growth of cancer cells in metastatic sites. Nat Rev Cancer. 2002; 2:563-72.

45. Fukumura D, Duda DG, Munn LL, Jain RK. Tumor microvasculature and microenvironment: novel insights through intravital imaging in pre-clinical models. Microcirculation. 2010; 17:206-25.

46. Hagendoorn J, Tong R, Fukumura D, Lin Q, Lobo J, Padera TP, Xu L, Kucherlapati R, Jain RK. Onset of abnormal blood and lymphatic vessel function and interstitial hypertension in early stages of carcinogenesis. Cancer Res. 2006; 66:3360-4.

47. Jain RK. Delivery of molecular and cellular medicine to solid tumors. Adv Drug Deliv Rev. 2012; 64:353-65.

48. Jain RK, Martin JD, Stylianopoulos T. The role of mechanical forces in tumor growth and therapy. Annu Rev Biomed Eng. 2014; 16:321-46.
49. Sen A, Capitano ML, Spernyak JA, Schueckler JT, Thomas S, Singh AK, Evans SS, Hylander BL, Repasky EA. Mild elevation of body temperature reduces tumor interstitial fluid pressure and hypoxia and enhances efficacy of radiotherapy in murine tumor models. Cancer Res. 2011; 71:3872-80.

50. Choi M, Kwok SJ, Yun SH. In vivo fluorescence microscopy: lessons from observing cell behavior in their native environment. Physiology (Bethesda). 2015; 30:40-9.

51. Vajkoczy $\mathrm{P}$, Menger MD, Vollmar B, Schilling L, Schmiedek P, Hirth KP, Ullrich A, Fong TA. Inhibition of tumor growth, angiogenesis, and microcirculation by the novel Flk-1 inhibitor SU5416 as assessed by intravital multifluorescence videomicroscopy. Neoplasia. 1999; 1:31-41.

52. Vajkoczy P, Ullrich A, Menger MD. Intravital fluorescence videomicroscopy to study tumor angiogenesis and microcirculation. Neoplasia. 2000; 2:53-61.

53. Ellenbroek SI, van Rheenen J. Imaging hallmarks of cancer in living mice. Nat Rev Cancer. 2014; 14:406-18.

54. Palmer GM, Fontanella AN, Shan S, Hanna G, Zhang G, Fraser CL, Dewhirst MW. In vivo optical molecular imaging and analysis in mice using dorsal window chamber models applied to hypoxia, vasculature and fluorescent reporters. Nat Protoc. 2011; 6:1355-66.

55. Turley RS, Fontanella AN, Padussis JC, Toshimitsu H, Tokuhisa Y, Cho EH, Hanna G, Beasley GM, Augustine CK, Dewhirst MW, Tyler DS. Bevacizumab-induced alterations in vascular permeability and drug delivery: a novel approach to augment regional chemotherapy for in-transit melanoma. Clin Cancer Res. 2012; 18:3328-39.

56. Baish JW, Gazit Y, Berk DA, Nozue M, Baxter LT, Jain RK. Role of tumor vascular architecture in nutrient and drug delivery: an invasion percolation-based network model. Microvasc Res. 1996; 51:327-46.

57. Yuan F, Leunig M, Berk DA, Jain RK. Microvascular permeability of albumin, vascular surface area, and vascular volume measured in human adenocarcinoma LS174T using dorsal chamber in SCID mice. Microvasc Res. 1993; 45:269-89.

58. Fisher DT, Appenheimer MM, Evans SS. The two faces of IL-6 in the tumor microenvironment. Semin Immunol. $2014 ; 26: 38-47$.

59. Nugent LJ, Jain RK. Monitoring transport in the rabbit ear chamber. Microvasc Res. 1982; 24:204-9.

60. Nugent LJ, Jain RK. Two-compartment model for plasma pharmacokinetics in individual blood vessels. J Pharmacokinet Biopharm. 1984; 12:451-61.

61. Primeau AJ, Rendon A, Hedley D, Lilge L, Tannock IF. The distribution of the anticancer drug Doxorubicin in relation to blood vessels in solid tumors. Clin Cancer Res. 2005; $11: 8782-8$.

62. Yuan F, Dellian M, Fukumura D, Leunig M, Berk DA, Torchilin VP, Jain RK. Vascular permeability in a human 
tumor xenograft: molecular size dependence and cutoff size. Cancer Res. 1995; 55:3752-6.

63. Hylander BL, Sen A, Beachy SH, Pitoniak R, Ullas S, Gibbs JF, Qiu J, Prey JD, Fetterly GJ, Repasky EA. Tumor priming by Apo2L/TRAIL reduces interstitial fluid pressure and enhances efficacy of liposomal gemcitabine in a patient derived xenograft tumor model. J Control Release. 2015; 217:160-9.

64. Chen K, Xu J, Luft JC, Tian S, Raval JS, DeSimone JM. Design of asymmetric particles containing a charged interior and a neutral surface charge: comparative study on in vivo circulation of polyelectrolyte microgels. J Am Chem Soc. 2014; 136:9947-52.

65. van de Ven AL, Kim P, Haley O, Fakhoury JR, Adriani G, Schmulen J, Moloney P, Hussain F, Ferrari M, Liu X, Yun SH, Decuzzi P. Rapid tumoritropic accumulation of systemically injected plateloid particles and their biodistribution. J Control Release. 2012; 158:148-55.

66. Yamatodani T, Holmqvist B, Kjellen E, Johnsson A, Mineta H, Wennerberg J. Using intravital microscopy to observe bevacizumab-mediated anti-angiogenesis in human head and neck squamous cell carcinoma xenografts. Acta Otolaryngol. 2012; 132:1324-33.

67. Campbell JJ, Hedrick J, Zlotnik A, Siani MA, Thompson DA, Butcher EC. Chemokines and the arrest of lymphocytes rolling under flow conditions. Science. 1998; 279:381-4.

68. Grayson MH, Hotchkiss RS, Karl IE, Holtzman MJ, Chaplin DD. Intravital microscopy comparing T lymphocyte trafficking to the spleen and the mesenteric lymph node. Am J Physiol Heart Circ Physiol. 2003;284:H2213-26.

69. Leunig M, Yuan F, Menger MD, Boucher Y, Goetz AE, Messmer K, Jain RK. Angiogenesis, microvascular architecture, microhemodynamics, and interstitial fluid pressure during early growth of human adenocarcinoma LS174T in SCID mice. Cancer Res. 1992; 52:6553-60.

70. Henderson RB, Lim LH, Tessier PA, Gavins FN, Mathies M, Perretti M, Hogg N. The use of lymphocyte function-associated antigen (LFA)-1-deficient mice to determine the role of LFA-1, Mac-1, and alpha4 integrin in the inflammatory response of neutrophils. J Exp Med. 2001; 194:219-26.

71. Mempel TR, Bauer CA. Intravital imaging of CD8+ T cell function in cancer. Clin Exp Metastasis. 2009; 26:311-27.

72. Mempel TR, Henrickson SE, Von Andrian UH. T-cell priming by dendritic cells in lymph nodes occurs in three distinct phases. Nature. 2004; 427:154-9.

73. Coulie PG, Van den Eynde BJ, van der Bruggen P, Boon T. Tumour antigens recognized by $\mathrm{T}$ lymphocytes: at the core of cancer immunotherapy. Nat Rev Cancer. 2014; 14:135-46.

74. Rosenberg SA, Restifo NP, Yang JC, Morgan RA, Dudley ME. Adoptive cell transfer: a clinical path to effective cancer immunotherapy. Nat Rev Cancer. 2008; 8:299-308.
75. Choi HS, Ha SY, Kim HM, Ahn SM, Kang MS, Kim KM, Choi MG, Lee JH, Sohn TS, Bae JM, Kim S, Kang ES. The prognostic effects of tumor infiltrating regulatory $\mathrm{T}$ cells and myeloid derived suppressor cells assessed by multicolor flow cytometry in gastric cancer patients. Oncotarget. 2016; 7:7940-51. https://doi.org/10.18632/oncotarget.6958.

76. Galon J, Costes A, Sanchez-Cabo F, Kirilovsky A, Mlecnik B, Lagorce-Pagès C, Tosolini M, Camus M, Berger A, Wind $\mathrm{P}$, Zinzindohoué F, Bruneval $\mathrm{P}$, Cugnenc PH, et al. Type, density, and location of immune cells within human colorectal tumors predict clinical outcome. Science. 2006; 313:1960-4.

77. Ibrahim EM, Al-Foheidi ME, Al-Mansour MM, Kazkaz GA. The prognostic value of tumor-infiltrating lymphocytes in triple-negative breast cancer: a meta-analysis. Breast Cancer Res Treat. 2014; 148:467-76.

78. Ladányi A, Kiss J, Somlai B, Gilde K, Fejos Z, Mohos A, Gaudi I, Tímár J. Density of DC-LAMP(+) mature dendritic cells in combination with activated $\mathrm{T}$ lymphocytes infiltrating primary cutaneous melanoma is a strong independent prognostic factor. Cancer Immunol Immunother. 2007; 56:1459-69.

79. Park IH, Kong SY, Ro JY, Kwon Y, Kang JH, Mo HJ, Jung SY, Lee S, Lee KS, Kang HS, Lee E, Joo J, Ro J. Prognostic Implications of Tumor-Infiltrating Lymphocytes in Association With Programmed Death Ligand 1 Expression in Early-Stage Breast Cancer. Clin Breast Cancer. 2016; 16:51-8.

80. Piras F, Colombari R, Minerba L, Murtas D, Floris C, Maxia C, Corbu A, Perra MT, Sirigu P. The predictive value of CD8, CD4, CD68, and human leukocyte antigen-D-related cells in the prognosis of cutaneous malignant melanoma with vertical growth phase. Cancer. 2005; 104:1246-54.

81. Chen Q, Appenheimer MM, Muhitch JB, Fisher DT, Clancy KA, Miecznikowski JC, Wang WC, Evans SS. Thermal facilitation of lymphocyte trafficking involves temporal induction of intravascular ICAM-1. Microcirculation. 2009; 16:143-58.

82. Mikucki ME, Skitzki JJ, Frelinger JG, Odunsi K, Gajewski TF, Luster AD, Evans SS. Unlocking tumor vascular barriers with CXCR3: Implications for cancer immunotherapy. OncoImmunology. 2016; 5:e1116675.

83. Fernandis AZ, Cherla RP, Ganju RK. Differential regulation of CXCR4-mediated T-cell chemotaxis and mitogenactivated protein kinase activation by the membrane tyrosine phosphatase, CD45. J Biol Chem. 2003; 278:9536-43.

84. Kucia M, Jankowski K, Reca R, Wysoczynski M, Bandura L, Allendorf DJ, Zhang J, Ratajczak J, Ratajczak MZ. CXCR4-SDF-1 signalling, locomotion, chemotaxis and adhesion. J Mol Histol. 2004; 35:233-45.

85. Xu Y, Hyun YM, Lim K, Lee H, Cummings RJ, Gerber SA, Bae S, Cho TY, Lord EM, Kim M. Optogenetic control of chemokine receptor signal and T-cell migration. Proc Natl Acad Sci U S A. 2014; 111:6371-6. 
86. Dovas A, Patsialou A, Harney AS, Condeelis J, Cox D. Imaging interactions between macrophages and tumour cells that are involved in metastasis in vivo and in vitro. $\mathrm{J}$ Microsc. 2013; 251:261-9.

87. Bajenoff M, Granjeaud S, Guerder S. The strategy of T cell antigen-presenting cell encounter in antigen-draining lymph nodes revealed by imaging of initial T cell activation. J Exp Med. 2003; 198:715-24.

88. Katakai T, Hara T, Lee JH, Gonda H, Sugai M, Shimizu A. A novel reticular stromal structure in lymph node cortex: an immuno-platform for interactions among dendritic cells, T cells and B cells. Int Immunol. 2004; 16:1133-42.

89. Ingulli $\mathrm{E}$, Mondino A, Khoruts A, Jenkins MK. In vivo detection of dendritic cell antigen presentation to $\mathrm{CD} 4(+)$ T cells. J Exp Med. 1997; 185:2133-41.

90. Ingulli E, Ulman DR, Lucido MM, Jenkins MK. In situ analysis reveals physical interactions between $\mathrm{CD} 11 \mathrm{~b}+$ dendritic cells and antigen-specific CD4 T cells after subcutaneous injection of antigen. J Immunol. 2002; 169:2247-52.

91. Lindquist RL, Shakhar G, Dudziak D, Wardemann H, Eisenreich T, Dustin ML, Nussenzweig MC. Visualizing dendritic cell networks in vivo. Nat Immunol. 2004; 5:1243-50.

92. Sixt M, Kanazawa N, Selg M, Samson T, Roos G, Reinhardt DP, Pabst R, Lutz MB, Sorokin L. The conduit system transports soluble antigens from the afferent lymph to resident dendritic cells in the $\mathrm{T}$ cell area of the lymph node. Immunity. 2005; 22:19-29.

93. Carriere V, Colisson R, Jiguet-Jiglaire C, Bellard E, Bouche G, Al Saati T, Amalric F, Girard JP, M'Rini C. Cancer cells regulate lymphocyte recruitment and leukocyte-endothelium interactions in the tumor-draining lymph node. Cancer Res. 2005; 65:11639-48.

94. Qian BZ, Pollard JW. Macrophage diversity enhances tumor progression and metastasis. Cell. 2010; 141:39-51.

95. Wyckoff JB, Wang Y, Lin EY, Li JF, Goswami S, Stanley ER, Segall JE, Pollard JW, Condeelis J. Direct visualization of macrophage-assisted tumor cell intravasation in mammary tumors. Cancer Res. 2007; 67:2649-56.

96. Goswami S, Sahai E, Wyckoff JB, Cammer M, Cox D, Pixley FJ, Stanley ER, Segall JE, Condeelis JS. Macrophages promote the invasion of breast carcinoma cells via a colony-stimulating factor-1/epidermal growth factor paracrine loop. Cancer Res. 2005; 65:5278-83. https://doi.org/10.1158/0008-5472.CAN-04-1853.

97. Lin HH, Stacey M, Saxby C, Knott V, Chaudhry Y, Evans D, Gordon S, McKnight AJ, Handford P, Lea S. Molecular analysis of the epidermal growth factor-like short consensus repeat domain-mediated protein-protein interactions: dissection of the CD97-CD55 complex. J Biol Chem. 2001; 276:24160-9.
98. Wyckoff J, Wang W, Lin EY, Wang Y, Pixley F, Stanley ER, Graf T, Pollard JW, Segall J, Condeelis J. A paracrine loop between tumor cells and macrophages is required for tumor cell migration in mammary tumors. Cancer Res. 2004; 64:7022-29.

99. Roussos ET, Balsamo M, Alford SK, Wyckoff JB, Gligorijevic B, Wang Y, Pozzuto M, Stobezki R, Goswami S, Segall JE, Lauffenburger DA, Bresnick AR, Gertler FB, Condeelis JS. Mena invasive (MenaINV) promotes multicellular streaming motility and transendothelial migration in a mouse model of breast cancer. J Cell Sci. $2011 ; 124: 2120-31$.

100. Roussos ET, Condeelis JS, Patsialou A. Chemotaxis in cancer. Nat Rev Cancer. 2011; 11:573-87.

101. Gul N, Babes L, Siegmund K, Korthouwer R, Bogels M, Braster R, Vidarsson G, ten Hagen TL, Kubes P, van Egmond M. Macrophages eliminate circulating tumor cells after monoclonal antibody therapy. J Clin Invest. 2014; 124:812-23.

102. Joyce JA, Pollard JW. Microenvironmental regulation of metastasis. Nat Rev Cancer. 2009; 9:239-52.

103. Padera TP, Kadambi A, di Tomaso E, Carreira CM, Brown EB, Boucher Y, Choi NC, Mathisen D, Wain J, Mark EJ, Munn LL, Jain RK. Lymphatic metastasis in the absence of functional intratumor lymphatics. Science. 2002; 296:1883-86.

104. Giampieri S, Manning C, Hooper S, Jones L, Hill CS, Sahai E. Localized and reversible TGFbeta signalling switches breast cancer cells from cohesive to single cell motility. Nat Cell Biol. 2009; 11:1287-96.

105. Matise LA, Palmer TD, Ashby WJ, Nashabi A, Chytil A, Aakre M, Pickup MW, Gorska AE, Zijlstra A, Moses HL. Lack of transforming growth factor-beta signaling promotes collective cancer cell invasion through tumor-stromal crosstalk. Breast Cancer Res. 2012; 14:R98.

106. Giampieri S, Pinner S, Sahai E. Intravital imaging illuminates transforming growth factor beta signaling switches during metastasis. Cancer Res. 2010; 70:3435-9.

107. Spicer JD, McDonald B, Cools-Lartigue JJ, Chow SC, Giannias B, Kubes P, Ferri LE. Neutrophils promote liver metastasis via Mac-1-mediated interactions with circulating tumor cells. Cancer Res. 2012; 72:3919-27.

108. Jabbour JM, Saldua MA, Bixler JN, Maitland KC. Confocal endomicroscopy: instrumentation and medical applications. Ann Biomed Eng. 2012; 40:378-97.

109. Polglase AL, McLaren WJ, Skinner SA, Kiesslich R, Neurath MF, Delaney PM. A fluorescence confocal endomicroscope for in vivo microscopy of the upper- and the lower-GI tract. Gastrointest Endosc. 2005; 62:686-95.

110. Kiesslich R, Gossner L, Goetz M, Dahlmann A, Vieth M, Stolte M, Hoffman A, Jung M, Nafe B, Galle PR, Neurath MF. In vivo histology of Barrett's esophagus and associated neoplasia by confocal laser endomicroscopy. Clin Gastroenterol Hepatol. 2006; 4:979-87. 
111. Nakao M, Yoshida S, Tanaka S, Takemura Y, Oka S, Yoshihara M, Chayama K. Optical biopsy of early gastroesophageal cancer by catheter-based reflectance-type laser-scanning confocal microscopy. J Biomed Opt. 2008; 13:054043.

112. Xie XJ, Li CQ, Zuo XL, Yu T, Gu XM, Li Z, Ji R, Wang Q, Li YQ. Differentiation of colonic polyps by confocal laser endomicroscopy. Endoscopy. 2011; 43:87-93.

113. Hsiung PL, Hardy J, Friedland S, Soetikno R, Du CB, Wu AP, Sahbaie P, Crawford JM, Lowe AW, Contag CH, Wang TD. Detection of colonic dysplasia in vivo using a targeted heptapeptide and confocal microendoscopy. Nat Med. 2008; 14:454-8.

114. Sturm MB, Joshi BP, Lu S, Piraka C, Khondee S, Elmunzer BJ, Kwon RS, Beer DG, Appelman HD, Turgeon DK, Wang TD. Targeted imaging of esophageal neoplasia with a fluorescently labeled peptide: first-in-human results. Sci Transl Med. 2013; 5:184ra61.

115. Thekkek N, Maru DM, Polydorides AD, Bhutani MS, Anandasabapathy S, Richards-Kortum R. Pre-clinical evaluation of fluorescent deoxyglucose as a topical contrast agent for the detection of Barrett's-associated neoplasia during confocal imaging. Technol Cancer Res Treat. 2011; 10:431-41.

116. Lopez A, Liao JC. Emerging endoscopic imaging technologies for bladder cancer detection. Curr Urol Rep. 2014; 15:406.

117. Adams W, Wu K, Liu JJ, Hsiao ST, Jensen KC, Liao JC. Comparison of 2.6- and 1.4-mm imaging probes for confocal laser endomicroscopy of the urinary tract. J Endourol. 2011; 25:917-21.

118. Chang TC, Liu JJ, Hsiao ST, Pan Y, Mach KE, Leppert JT, McKenney JK, Rouse RV, Liao JC. Interobserver agreement of confocal laser endomicroscopy for bladder cancer. J Endourol. 2013; 27:598-603.

119. Wu K, Liu JJ, Adams W, Sonn GA, Mach KE, Pan Y, Beck AH, Jensen KC, Liao JC. Dynamic real-time microscopy of the urinary tract using confocal laser endomicroscopy. Urology. 2011; 78:225-31.

120. Gong Y. Pathologic aspects of inflammatory breast cancer: part 2. Biologic insights into its aggressive phenotype. Semin Oncol. 2008; 35:33-40.

121. Resetkova E. Pathologic aspects of inflammatory breast carcinoma: part 1. Histomorphology and differential diagnosis. Semin Oncol. 2008; 35:25-32.

122. Ceelen WP, Bracke ME. Peritoneal minimal residual disease in colorectal cancer: mechanisms, prevention, and treatment. Lancet Oncol. 2009; 10:72-79.
123. Davies JM, O'Neil B. Peritoneal carcinomatosis of gastrointestinal origin: natural history and treatment options. Expert Opin Investig Drugs. 2009; 18:913-9.

124. Aoyagi T, Terracina KP, Raza A, Takabe K. Current treatment options for colon cancer peritoneal carcinomatosis. World J Gastroenterol. 2014; 20:12493-500.

125. Francescutti V, Rivera L, Seshadri M, Kim M, Haslinger M, Camoriano M, Attwood K, Kane JM 3rd, Skitzki JJ. The benefit of intraperitoneal chemotherapy for the treatment of colorectal carcinomatosis. Oncol Rep. 2013; 30:35-42.

126. Verwaal VJ, Bruin S, Boot H, van Slooten G, van Tinteren H. 8-year follow-up of randomized trial: cytoreduction and hyperthermic intraperitoneal chemotherapy versus systemic chemotherapy in patients with peritoneal carcinomatosis of colorectal cancer. Ann Surg Oncol. 2008; 15:2426-32.

127. Chudgar AV, Mankoff DA. Molecular Imaging and Precision Medicine in Breast Cancer. PET Clin. 2017; 12:39-51.

128. Bilgin B, Sendur MA, Bulent Akinci M, Sener Dede D, Yalcin B. Targeting the PD-1 pathway: a new hope for gastrointestinal cancers. Curr Med Res Opin. 2017; 33:749-59.

129. Toh JWT, de Souza P, Lim SH, Singh P, Chua W, Ng W, Spring KJ. The Potential Value of Immunotherapy in Colorectal Cancers: Review of the Evidence for Programmed Death-1 Inhibitor Therapy. Clin Colorectal Cancer. 2016; 15:285-91.

130. Gabriel EM, Lattime EC. Anti-CTL-associated antigen 4: are regulatory T cells a target? Clin Cancer Res. 2007; 13:785-8.

131. Sharma P, Wagner K, Wolchok JD, Allison JP. Novel cancer immunotherapy agents with survival benefit: recent successes and next steps. Nat Rev Cancer. 2011; 11:805-12.

132. Robert C, Ribas A, Wolchok JD, Hodi FS, Hamid O, Kefford R, Weber JS, Joshua AM, Hwu WJ, Gangadhar TC, Patnaik A, Dronca R, Zarour H. Anti-programmeddeath-receptor-1 treatment with pembrolizumab in ipilimumab-refractory advanced melanoma: a randomised dose-comparison cohort of a phase 1 trial. Lancet. 2014; 384:1109-17.

133. O'Donnell JS, Long GV, Scolyer RA, Teng MW, Smyth MJ. Resistance to PD1/PDL1 checkpoint inhibition. Cancer Treat Rev. 2017; 52:71-81. 